\title{
Análise e avaliação do mercado reprimido de energia no contexto do desenvolvimento limpo na Região Administrativa de Araçatuba*
}

\author{
Raphael Bertrand Heideier** \\ Marcos Z. Ueocka*** \\ Miguel Edgar Morales Udaeta****
}

Sumário: 1. Caracterização da região; 2. Mercado reprimido de energia na RAA; 3. Conclusões.

Summary: 1 . Characterization of the region; 2 . Restrained energy market in the Araçatuba Administrative Region; 3. Conclusions.

Palavras-chave: demanda reprimida; desenvolvimento limpo; energia; Região Administrativa de Araçatuba.

Key words: restrained demand; clean development; energy; Araçatuba Administrative Region.

Este artigo avalia o mercado reprimido de eletricidade, gás natural e álcool na Região Administrativa de Araçatuba (RAA), comparando o consumo com o consumo médio

\footnotetext{
* Artigo recebido em set. 2008 e aceito em abr. 2009. Os autores agradecem à Fapesp (Fundação de Apoio à Pesquisa do Estado de São Paulo), que possibilitou este artigo através do projeto de pesquisa 03/06441-7; e à ANP (Agência Nacional do Petróleo, Gás Natural e Biocombustíveis) pelo apoio através do Programa Recursos Humanos PRH-ANP/04.

** Pesquisador. Mestrando em engenharia de energia do Departamento de Engenharia de Energia e Automação Elétricas da Escola Politécnica da Universidade de São Paulo (Epusp). Endereço: Av. Prof. Luciano Gualberto, Travessa 3, 158 - Cidade Universitária - CEP 05508-970, São Paulo, SP, Brasil. E-mail: rbheideier@yahoo.com.br.

*** Pesquisador. Aluno de engenharia e automação elétrica do Departamento de Engenharia de Energia e Automação Elétricas da Escola Politécnica da Universidade de São Paulo (Epusp). Endereço: Av. Prof. Luciano Gualberto, travessa 3, 158 - Cidade Universitária - CEP 05508-970, São Paulo, SP, Brasil. E-mail: marcos.ueocka@poli.usp.br.

***** Professor. Pós-doutor em planejamento estratégico pela Universidade de São Paulo (USP), doutor em engenharia elétrica pela USP, mestre em engenharia elétrica pela USP. Endereço: Instituto de Eletrotécnica e Energia da USP (IEE/USP) — Avenida Prof. Luciano Gualberto, 1289 — Cidade Universitária — CEP 05508-010, Butantã, São Paulo, SP, Brasil. E-mail: udaeta@pea. usp.br.
} 
do estado de São Paulo e do estado da Flórida, EUA, onde se acredita que a demanda é plenamente satisfeita. $\mathrm{O}$ artigo apresenta uma projeção para o atendimento da demanda no contexto do desenvolvimento limpo em um cenário hipotético.

Analysis and assessment of the restrained energy market in the clean development context of the Araçatuba Administrative Region

This article assesses the restrained market of electricity, natural gas and alcohol in the Araçatuba Administrative Region (RAA), comparing the its consumption with the average consumption of the states of São Paulo and Florida (USA), where the demand is believed to be fully satisfied. Projections are made for answering the demand in a clean development context for a hypothetical scenario.

\section{Caracterização da região}

Localizada no oeste do estado de São Paulo, a Região Administrativa de Araçatuba (RAA) é composta por 43 municípios e a região abrange 7\% do território estadual. O município de Araçatuba é a sede e o maior polo da região, concentrando 25,3\% da população. Juntamente com Birigui, Andradina e Penápolis, em 2005, abrigava 56,6\% da população regional conforme dados do Instituto Brasileiro de Geografia e Estatística (IBGE, 2008).

A RAA apresenta a terceira menor densidade demográfica (37 habitantes $/ \mathrm{km}^{2}$ em 2002) e apresenta a segunda menor taxa de crescimento populacional do estado. Entre 2000 e 2005, a população cresceu 1\% ao ano, atingindo aproximadamente 733.963 habitantes (IBGE), o que representa apenas $1,8 \%$ da população paulista no mesmo ano. A maioria da população $(91,5 \%)$ reside em áreas urbanas, índice inferior à média estadual $(93,4 \%)$, já que $40 \%$ dos municípios apresentam taxas de urbanização inferiores a $80 \%$.

O PIB do estado de São Paulo apresentou uma expansão, no período de 2002 a 2005, de 12,4\% em média (IBGE, 2008). No mesmo período a RAA apresentou taxa de $8,5 \%$.

O setor de serviços é o que tem maior participação no PIB de Araçatuba, segundo pesquisa do Seade (Sistema Estadual de Análise de Dados) e do IBGE, correspondendo a $62 \%$ da riqueza do município. Em 2005, o PIB local foi de $\mathrm{R} \$ 1.369,20$ milhões e o valor adicionado do segmento de serviços foi de 9,6\% em média nos últimos três anos. Nos serviços, destacam-se os serviços pessoais, atividades assistenciais e coletivas, os serviços de saúde e a educação formal. Em seguida vem o segmento da indústria, com $\mathrm{R} \$ 290,47$ milhões; e o da agropecuária, com apenas $\mathrm{R} \$ 38,60$ milhões. 
Destaca-se, ainda, na geração do valor adicionado industrial, a fabricação e o refino de petróleo e álcool (17\%). Assim como nas demais RAs do oeste paulista, a importância dessa atividade vem da produção de álcool.

\section{Energia elétrica}

O município de Araçatuba é importante centro educacional na região e Ilha Solteira também possui importantes instituições de ensino superior. A hidrelétrica Engenheiro Souza Dias, localizada em Castilho, e a Três Irmãos, em Pereira Barreto, formam, com a Usina Hidrelétrica de Ilha Solteira, um dos maiores complexos hidrelétricos do mundo, responsável por $25 \%$ da energia produzida no estado.

Em 2005 o consumo de energia elétrica, incluindo autoprodutores, foi de $118.439 \mathrm{GWh}$, registrando um crescimento de 6,7\% em relação ao ano anterior (111.011 GWh). A RAA apresentou consumo de 873,77 GWh em 2002, representando cerca de $1 \%$ do consumo do estado no mesmo ano. O consumo anual de energia elétrica por ligação no comércio, na agricultura e nos serviços diminuiu de 8,7 MW para 7,1 MW; com a média do estado, em 2002, de 13,8 MW. O consumo por ligação residencial manteve-se abaixo da meta de racionamento estabelecida para 2001, ou seja, a redução do consumo foi maior do que $20 \%$, variando de 2,3 MW para 1,8 MW em 2002, com a média do estado de 2,1 MW.

\section{Gás natural}

Até agosto de 2007, o volume de gás canalizado distribuído no estado de São Paulo pela Comgás - Companhia de Gás de São Paulo; Gás Natural São Paulo Sul; e Gás Brasiliano Distribuidora Ltda. foi de $460.104 \mathrm{mil} \mathrm{m}^{3}$ de gás natural (GN), superando em 7,5\% o montante de $427.826 \mathrm{mil} \mathrm{m}^{3}$ mensais registrado no mesmo período de 2006.

Com $81,1 \%$ do mercado total, o setor industrial registrou até o mês de agosto de 2007, um consumo mensal de $372.157 \mathrm{mil} \mathrm{m}^{3}$ de gás canalizado, resultando em um incremento de $9,2 \%$ em relação ao mesmo período do ano anterior. Para o setor residencial foram distribuídos $995 \mathrm{mil} \mathrm{m}^{3}$ de gás canalizado, cujo montante representou $2,2 \%$ do mercado total e uma evolução de $4,6 \%$ com relação ao mesmo período do ano anterior. E para o setor comercial um volume mensal de $8.327 \mathrm{mil} \mathrm{m}^{3}$ de gás canalizado, cujo montante repre- 
sentou 1,8\% do mercado total. Em relação ao mesmo período do ano anterior, este setor evoluiu $0,8 \%$.

\section{Indústria sucroalcooleira}

A Conab estima que a colheita da safra 2008/2009 deverá variar entre 607,8 milhões e 631,5 milhões de toneladas, número entre 8,8\% e 13,1\% acima da safra do ano passado. Com aproximadamente 55\% para produção de biocombustíveis, ou seja, de 26,4 bilhões a 27,4 bilhões de litros de álcool, 44\% para açúcar e o restante na fabricação de cachaça, rapadura, alimento para gado, sementes e mudas (Conab, 2008). Além da área plantada ter aumentado de 7 milhões para 7,8 milhões de hectares, crescimento principalmente sobre áreas de pastagens. Os principais motivos do crescimento seriam os investimentos em tecnologia nas usinas de cana-de-açúcar, o plantio de variedades mais produtivas e o clima favorável (Conab, 2008).

O estado de São Paulo, em especial, responde por $57 \%$ da produção brasileira de cana, e seu cultivo é concentrado no oeste paulista, como se observa na figura. A RAA contribuiu com 7,3\%, 7,4\% e 7,9\%, respectivamente, no total das safras de 2004/2005, 2005/2006 e 2006/2007 do estado de São Paulo segundo dados da Única (Udop, 2008). Considerando que a RAA participa hoje com cerca de $8 \%$ da safra total e igual proporção de área plantada de cana, ou seja, $3.557 \mathrm{~km}^{2}$, o cultivo de cana representa 19\% do território da RAA.

Plantações de cana-de-açúcar na região Centro-Sul

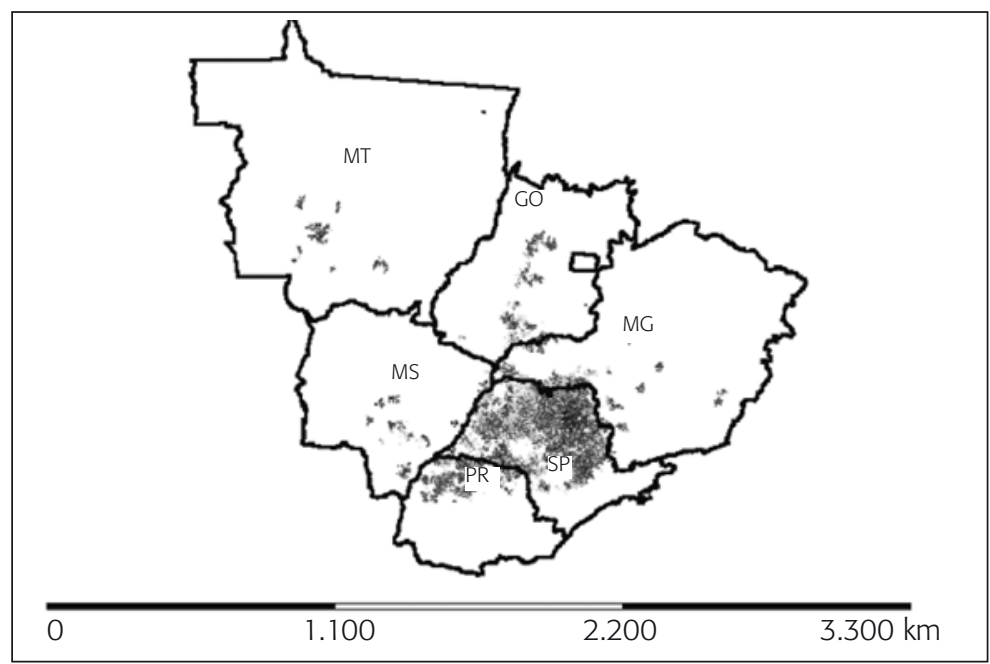


O programa norte-americano de reformulação da gasolina, sobretudo a partir de 2004, quando o MTBE ${ }^{1}$ foi banido na Califórnia (EUA) e teve sua proibição estendida rapidamente a outros estados norte-americanos e a outros países, consolidou o etanol como aditivo para a gasolina e conferiu novas dimensões ao uso combustível do produto (Conab, 2008).

O mundo questiona alguns pontos quanto ao emprego dos biocombustíveis. A redução de emissão de GEE e outros poluentes em substituição a combustíveis fósseis é inquestionável, mas existe uma preocupação quanto à real taxa de redução e principalmente quanto à eventual queima de "estoques de carbonos" para a formação de lavouras. Existe ainda uma preocupação em relação à concorrência do cultivo para fins de abastecimento da demanda de alimento e a geração de biocombustível. Por fim, são questionados os impactos socioambientais a serem vividos por países em desenvolvimento, consequentes da produção de biocombustíveis em grande escala, como mudanças no uso da terra, eventual degradação de ecossistemas, impacto sobre a pobreza e futuro dos pequenos produtores.

A empresa de pesquisas brasileira Embrapa concluiu que a plantação de cana-de-açúcar absorve muito mais gás carbônico quando substitui a de soja ou pasto para gado, porque tem maior capacidade que outras culturas de converter o gás em biomassa (BBC Brasil, 2008).

Estudos mostram que o álcool da cana-de-açúcar do Brasil se sai bem em termos de impacto ambiental em comparação com o álcool de milho, dos Estados Unidos, ou com o óleo de dendê, da Malásia, quando levados em conta outros fatores da produção (Leite, 2005).

Dados da Conab mostram que o país tem hoje 276 milhões de hectares de terras cultiváveis. Destes, $72 \%$ estão ocupados por pastagens, $16,9 \%$ por grãos e $2,8 \%$ por cana-de-açúcar, o que demonstra o potencial de crescimento da atividade sem interferir em áreas protegidas, áreas de pastagem ou áreas destinadas ao cultivo de outras culturas. Além disso, o emprego de tecnologias já disponíveis como a hidrólise, porém ainda não utilizadas comercialmente, podem dobrar a capacidade de produção de álcool utilizando a mesma área plantada ou aumentar a produção aproximadamente seis vezes sem restringir outras atividades.

\footnotetext{
${ }^{1}$ O MTBE, ou éter metil-t-butílico, é um éter sintético usado desde 1979 na gasolina sem chumbo para oxigenar e aumentar a octanagem, podendo ter teores de $11 \%$. Seu uso foi proibido por razões ambientais e de saúde.
} 
Há vários projetos de investimento em curso no Brasil e no mundo para elevar a capacidade instalada de produção de álcool via cana-de-açúcar ou outras matérias-primas. A principal tecnologia neste sentido, desenvolvida no Brasil, é a DHR (Dedini hidrólise rápida) para produção de álcool utilizando o bagaço da cana-de-açúcar, desenvolvida pela Dedini S/A Indústrias de Base em parceria com a Copersucar e a Fundação de Amparo à Pesquisa do Estado de São Paulo (Fapesp). Esta tecnologia está patenteada em vários países e reduz o custo do álcool combustível em até $40 \%$, dobra a produção sem a necessidade de aumentar a área plantada. A palha da cana, que atualmente é queimada para facilitar o corte no campo e corresponde a $1 / 3$ do volume da safra de cana, pode substituir o bagaço na geração de energia elétrica (Ometto, 2003).

O emprego do álcool etílico para fins carburantes não se limita, hoje, aos veículos biocombustíveis, chamados flex, que funcionam com misturas de qualquer proporção de álcool e gasolina, mas também pode ser usado em aeronaves pequenas e ônibus (MDIC, 2008).

As principais tecnologias que constituem as inovações disponíveis para viabilizar o melhor aproveitamento dos recursos energéticos da biomassa na geração de energia elétrica pelo setor sucroalcooleiro são apresentadas na tabela 1 (EPE, 2007b).

Tabela 1

Geração específica de energia elétrica a partir da biomassa

\begin{tabular}{|lcc|}
\hline kWh/t biomassa* em & Cogeração & Geração pura \\
\hline Ciclo a vapor de baixa eficiência (sistemas atualmente utilizados) & 15 & - \\
Ciclo a vapor com turbinas de contrapressão & 215 & \\
Ciclo a vapor com turbinas de condensação e extração & 340 & 530 \\
Ciclo combinado integrado à gaseificação da biomassa & 1.050 & 1.150 \\
\hline
\end{tabular}

Fonte: EPE.

* Referenciado à biomassa em base seca.

A grande ameaça do avanço massivo da utilização do álcool de canade-açúcar, no Brasil, é o impacto social que a mecanização dos campos trará se não forem tomadas medidas emergenciais para preparar os cortadores de cana, chamados boias-frias, para o desenvolvimento de outra atividade que lhes traga renda ou algum tipo de reforma agrária para fixá-los à terra. 


\section{Mercado reprimido de energia na RAA}

No comércio, nas residências e no campo certamente existe demanda reprimida no consumo de energia elétrica por existir intenção, por parte dos consumidores, de adquirir e utilizar equipamentos elétricos para prover mais conforto ou lazer, e até de domicílios sem acesso à oferta de energético como eletricidade, gás ou álcool.

Como apresentado na tabela 2, a exemplo da energia elétrica, a discrepância no consumo de energia ao redor do mundo não pode ser explicada apenas pelo acesso à energia. Fatores climáticos e culturais exercem uma influência muito grande no consumo.

Tabela 2

Consumo de energia no mundo

\begin{tabular}{|c|c|c|c|c|c|c|c|}
\hline \multicolumn{4}{|c|}{ 2004: os 10 países com o maior IDH } & \multicolumn{4}{|c|}{ 2004: os 10 países com o menor IDH } \\
\hline \multirow[t]{2}{*}{ País } & \multirow[t]{2}{*}{$\mathrm{IDH}$} & \multicolumn{2}{|c|}{$\begin{array}{l}\text { Consumo anual } \\
\text { de eletricidade } \\
\text { por habitante } \\
(\mathrm{kWh})\end{array}$} & \multirow[t]{2}{*}{ País } & \multirow[t]{2}{*}{ IDH } & \multicolumn{2}{|c|}{$\begin{array}{c}\text { Consumo anua } \\
\text { de eletricidade } \\
\text { por habitante } \\
(\mathrm{kWh})\end{array}$} \\
\hline & & 1980 & 2001 & & & 1980 & 2001 \\
\hline 1. Noruega & 0,956 & 22.400 & 29.290 & 168. R. D. do Congo & 0,365 & 161 & 93 \\
\hline 2. Suécia & 0,946 & 11.700 & 17.355 & 169. R. Centro Africana & 0,361 & 29 & 29 \\
\hline 3. Austrália & 0,946 & 6.599 & 11.205 & 170. Etiópia & 0,359 & & 30 \\
\hline 4. Canadá & 0,943 & 14.243 & 18.212 & 171. Moçambique & 0,354 & 364 & 70 \\
\hline 5. Holanda & 0,942 & 4.560 & 6.905 & 172. Guiné-Bissau & 0,350 & 18 & 43 \\
\hline 6. Bélgica & 0,942 & 5.177 & 8.818 & 173. Burundi & 0,339 & 12 & 73 \\
\hline 7. Islândia & 0,941 & 13.838 & 28.260 & 174. Mali & 0,326 & 15 & 34 \\
\hline 8. EUA & 0,939 & 10.336 & 13.241 & 175. Burkina Faso & 0,302 & 16 & 24 \\
\hline 9. Japão & 0,938 & 4.944 & 8.203 & 176. Nigéria & 0,292 & 39 & 41 \\
\hline 10. Irlanda & 0,936 & 3.106 & 6.417 & 177. Serra Leoa & 0,273 & 62 & 55 \\
\hline
\end{tabular}

Fonte: Pnud.

O estado da Flórida, nos EUA, está numa região bastante próxima da faixa tropical, onde se localiza a RAA. Portanto, para efeito de comparação com um país desenvolvido, atentando às condições climáticas, embora esse 
estado seja litorâneo e a RAA não, seria interessante tal comparação. Mas como o padrão de consumo no mundo está mudando e a RAA apresenta uma economia com uma série de entraves e particularidades para atingir esse perfil de consumo, para o cálculo de demanda reprimida será adotado também como parâmetros de referência o próprio estado de São Paulo.

\section{Energia elétrica}

Para estimativa da demanda reprimida de energia elétrica residencial foi observado que em média cada domicílio é habitado por três pessoas, tanto a média do estado de São Paulo como na RAA. Com base nesta informação, foi levantado o consumo mensal de um grupo de utensílios elétricos que uma casa simples teria para prover conforto aos seus moradores. Levando-se em conta que a região é um lugar quente estimou-se a demanda residencial modelo (tabela 3).

Tabela 3

Modelo de demanda para residência simples com três moradores na RAA

\begin{tabular}{|c|c|c|c|c|c|c|}
\hline \multirow{2}{*}{ Equipamento } & \multirow{2}{*}{ Qtde. } & \multirow{2}{*}{$\begin{array}{l}\text { Potência } \\
\text { (W) }\end{array}$} & \multicolumn{2}{|c|}{ Utilização } & \multicolumn{2}{|c|}{ Consumo } \\
\hline & & & Dias/Mês & Horas/Dia & kWh/Mês & kWh/Ano \\
\hline Geladeira & 1 & 200 & 30 & 18 & 108 & $1.296,0$ \\
\hline \multirow[t]{2}{*}{ Lâmpada } & 2 & 100 & 30 & 6 & 36 & 432,0 \\
\hline & 2 & 60 & 30 & 2 & 7,2 & 86,4 \\
\hline TV & 1 & 80 & 30 & 3 & 7,2 & 86,4 \\
\hline Som & 1 & 40 & 15 & 2 & 1,2 & 14,4 \\
\hline Ferro & 1 & 800 & 4 & 3 & 9,6 & 115,2 \\
\hline Chuveiro & 1 & 3.500 & 30 & 0,2 & 21 & 252,0 \\
\hline Ventilador & 1 & 100 & 20 & 5 & 10 & 120,0 \\
\hline Forninho & 1 & 1.200 & 15 & 0,4 & 7,2 & 86,4 \\
\hline Total & & & & & 207,4 & $2.488,8$ \\
\hline
\end{tabular}

Considerando a diferença entre a demanda do domicílio modelo e a demanda domiciliar de cada município, estimou-se o valor de 12.455 MWh mensais para suprir as 205.611 residências existentes na RAA.

O consumo médio por habitante na Flórida era de $536 \mathrm{kWh} / \mathrm{mês}$, e entre 2002 e 2007 foi estável. O número de habitantes por domicílio também 
ficou estável. Para o consumo médio por habitante na RAA de 48,16, a demanda reprimida em relação à Flórida seria de aproximadamente 306.797 MWh mensais, 10 vezes o consumo da RAA em 2002.

O déficit estimado de 60 mil ligações elétricas a ser atendido pelo programa "Luz para Todos" no estado de São Paulo, poderá atingir 90 mil ligações nos anos subsequentes, perfazendo quase 140 mil ligações efetuadas por meio dos programas de eletrificação rural, entre 1997 e 2009, em decorrência do natural incremento que programas desse porte provocam no mercado rural.

O grupo de consumidores rurais está fora do grupo residencial. Totalizando 13.949 consumidores em 2002, a população rural é estimada em 58.644 pessoas na RAA, conforme dados do IBGE e Saede. O consumo mensal médio deste grupo é de $121 \mathrm{kWh}$ por habitante, já o consumo residencial mensal médio é de $48 \mathrm{kWh}$ por habitante.

Considerando a média de habitantes por domicílio rural de referência igual à do município de Birigui, 3,5, foi estimado um total de 3.013 domicílios residenciais sem acesso à energia elétrica. O que representa 1.507 MWh por mês de consumo em relação à demanda de média de cada município.

Levando-se em conta a diferença entre a demanda média por domicílio rural do município de referência, no caso Birigui com o consumo de 608,5 kWh mensais, e a demanda de cada município, estimou-se o valor de 2.980 MWh mensais para suprir os 15.456 domicílios existentes na RAA, considerando-se as residências estimadas sem acesso à energia.

Assumindo a mesma metodologia adotada para o cálculo da demanda reprimida residencial em relação à Flórida para calcular a demanda reprimida rural da RAA, deve-se realizar o cálculo por município. Pois alguns municípios apresentam consumo superior ao consumo médio da Flórida e a demanda reprimida nesses municípios deve ser zero. Assim, estima-se cerca de 24.375 MWh mensais.

A maioria dos municípios possui um comércio que não supre totalmente a demanda por bens e serviços da população. Com isso a população precisa ir aos grandes centros urbanos para suprir suas necessidades.

É interessante observar que nenhum município na RAA possui consumo médio no comércio igual ou maior que a média do estado nesse setor. Com isso, será tomado como referência o consumo médio do comércio da cidade de

\footnotetext{
${ }^{2}$ O governo federal iniciou em 2004 o "Programa nacional de universalização do acesso e uso da energia elétrica - Luz para Todos" com o objetivo de levar energia elétrica para a população do meio rural.
} 
Araçatuba, porque é a cidade que oferece a maior diversidade e "qualidade" de serviços.

Para um consumo mensal médio de 866 kWh no comércio do município de Araçatuba, estimou-se uma demanda mensal reprimida de 4.270 MWh no comércio da RAA.

O consumo comercial na Flórida teve um crescimento médio de $0,86 \%$ ao ano entre 2002 e 2007. As previsões americanas indicam que o consumo médio por consumidor deve continuar crescendo indeterminadamente. Portanto, será considerado o consumo médio de 2007, que era cerca de 8.000 kWh por consumidor. Assim a demanda reprimida na RAA seria de 146.880 MWh.

O desenvolvimento da região seguindo o modelo americano ou europeu implica uma nova estrutura residencial. Por exemplo, em 2002 havia em média três pessoas por residência na RAA; na Flórida esse índice é de 2,2. Portanto, a projeção da demanda de energia elétrica a partir de 2002 foi feita com base na demanda per capita da região, considerando um cenário de rápido desenvolvimento em todos os setores da região até atingir em 2030 um padrão de consumo residencial e rural equivalente ao do estado da Flórida.

Tabela 4

Projeção do consumo de energia elétrica setorial para a RAA

\begin{tabular}{|lccccc|}
\hline Discriminação & 2010 & 2015 & 2020 & 2025 & 2030 \\
\hline População urbana & 678.777 & 713.401 & 749.792 & 788.039 & 828.237 \\
Consumo (kWh/hab. mês) & 96,0 & 147,6 & 227,2 & 349,5 & 537,8 \\
Total urbano (GW/ano) & 781,6 & $1.264,0$ & $2.044,0$ & $3.305,4$ & $5.345,2$ \\
População rural & 63.110 & 66.329 & 69.713 & 73.269 & 77.006 \\
Consumo (kWh/hab. mês) & 184,3 & 239,7 & 311,8 & 405,6 & 527,6 \\
Total rural (GW/ano) & 139,6 & 190,8 & 260,9 & 356,6 & 487,6 \\
Estabelecimentos comerciais & 19.990 & 19.990 & 19.990 & 19.990 & 19.990 \\
Consumo (kWh/estab. ano) & $15.820,1$ & $24.565,4$ & $38.144,9$ & $59.231,1$ & $91.973,5$ \\
Total comercial (GW/ano) & 316,2 & 491,1 & 762,5 & $1.184,0$ & $1.838,6$ \\
Estabelecimentos industriais & 3.840 & 4.451 & 5.160 & 5.982 & 6.935 \\
Consumo (kWh/estab. ano) & $110.713,5$ & $126.797,2$ & $145.217,5$ & $166.313,7$ & $190.474,7$ \\
Total industrial (GW/ano) & 425,1 & 564,4 & 749,3 & 994,9 & $1.320,9$ \\
Total geral (GW/ano) & $1.662,5$ & $2.510,3$ & $3.816,7$ & $5.840,9$ & $8.992,2$ \\
\hline
\end{tabular}

Observa-se que o consumo residencial urbano e rural é o setor que demanda mais energia nesse cenário, exigindo uma potência de 5.345 GWh de 
energia, seguido do setor comercial com quase $1.839 \mathrm{GW}$ e por fim o industrial com $1.321 \mathrm{GW}$. No total seriam necessários $8.992 \mathrm{GWh}$ ao ano no fornecimento de energia para a RAA ou uma capacidade instalada de $1.735 \mathrm{MW}$, $32 \%$ da capacidade instalada do complexo hidrelétrico da região.

\section{Gás natural}

Pela falta de dados disponíveis, a estimativa de demanda reprimida de gás na RAA foi feita sem segmentá-la por município. Para tanto, utilizou-se uma estimativa de consumo de cada setor da RAA por meio da distribuição de consumo setorial de toda a região de concessão da Gás Brasiliano Distribuidora (GBD). A divisão por setores para a GBD é dada na tabela 5, que em 2006 apresenta $90 \%$ distribuídos para indústria, $0,4 \%$ para o comércio, $0,2 \%$ residencial e 9\% GNV e GNC.

Tabela 5

Distribuição por setor da demanda anual da GBD

\begin{tabular}{|lrrr|}
\hline Milhões de $\mathrm{m}^{3}$ ao ano & $\mathbf{2 0 0 4}$ & $\mathbf{2 0 0 5}$ & $\mathbf{2 0 0 6}$ \\
\hline Industrial & 66,9 & 96,0 & 119,7 \\
Comercial & 0,4 & 0,5 & 0,5 \\
Residencial & 0,1 & 0,2 & 0,3 \\
GNV/GNC & 4,2 & 7,2 & 12,1 \\
Total & 71,5 & 103,9 & 132,6 \\
\hline
\end{tabular}

O total distribuído no city-gate de Bilac, o único que fornece para RAA, foi em média 1,64 milhão de $\mathrm{m}^{3}$ por mês em 2006.

Levando-se em conta a distribuição setorial de consumidores de energia elétrica de 2002, fornecida pela Saede, tem-se 3.031 consumidores industriais, 19.990 no comercial e 205.611 em residências.

Ponderando a demanda de gás da RAA pela distribuição setorial da GBD e dividindo o valor pelo número de consumidores estimou-se o consumo médio de gás mensal em $488,7 \mathrm{~m}^{3}$ para a indústria, $0,31 \mathrm{~m}^{3}$ para o comércio e 0,02 residencial.

Pela tabela 6, conclui-se que há demanda reprimida para todos os setores. Para que tais setores consumissem o equivalente à média de consumo do estado de São Paulo em 2006, seria necessário o fornecimento adicional mensal de 926,28 milhões de $\mathrm{m}^{3}$, da seguinte forma: 903,51 industrial; 18,80 
comercial; e 3,96 residencial. Equivale a dizer que o total transportado pelo Gasbol hoje deveria ser destinado para suprir a demanda reprimida da RAA.

Tabela 6

Consumo de gás natural no estado de São Paulo

\begin{tabular}{|lrrrrr|}
\hline Discriminação & \multicolumn{1}{c}{$\mathbf{2 0 0 3}$} & \multicolumn{1}{c}{$\mathbf{2 0 0 4}$} & \multicolumn{1}{c}{$\mathbf{2 0 0 5}$} & \multicolumn{1}{c}{$\mathbf{2 0 0 6}$} & \multicolumn{1}{c}{$\mathbf{2 0 0 7}$} \\
\hline Residencial & 20,0 & 20,5 & 19,3 & 19,3 & 18,4 \\
Industrial & $290.225,0$ & $290.806,9$ & $287.431,8$ & $298.580,5$ & $302.947,1$ \\
Comercial & 870,1 & 932,7 & 938,0 & 941,0 & 906,6 \\
Automotivo & $141.757,6$ & $139.113,0$ & $127.599,0$ & $129.117,1$ & $122.256,2$ \\
Cogeração & $1.828 .516,1$ & $1.593 .014,7$ & $1.430 .368,8$ & $1.335 .166,7$ & $1.309 .658,7$ \\
Termogeração & $5.546 .708,3$ & $3.107 .166,7$ & $6.161 .625,0$ & $266.9416,7$ & $2.116 .833,3$ \\
Total & $\mathbf{7 3 6 , 5}$ & $\mathbf{7 7 3 , 5}$ & $\mathbf{8 1 5 , 2}$ & $\mathbf{8 4 3 , 8}$ & $\mathbf{8 2 7 , 0}$ \\
\hline
\end{tabular}

Fonte: Secretaria de Saneamento e Energia.

Em primeiro lugar, com relação ao perfil de consumo das indústrias da região da RAA e do estado de São Paulo em geral, não é razoável admitir que seja o mesmo. Seria interessante realizar um estudo do perfil industrial da RAA e confrontar com o perfil do estado.

Outro problema é o limite de oferta de gás. O gasoduto Brasil-Bolívia transporta 30 milhões de $\mathrm{m}^{3}$ por dia e a GBD tem o direito de distribuir apenas $13,33 \%$ desse gás para a RAA. Ou seja, nem o total transportado pelo gasoduto é suficiente para atender à demanda estimada para o padrão médio de consumo do estado de São Paulo.

Logo, foi feita outra estimativa utilizando a mesma metodologia, mas apenas para as cidades com mais de 90 mil habitantes na região urbana, ou seja, Araçatuba e Birigui. E o consumo médio das indústrias foi utilizando a estimativa apresentada pelo plano de negócio da GBD, em média $130 \mathrm{mil} \mathrm{m}^{3}$ mensais.

Para as cidades citadas, os números de consumidores por setor são 1.557 industriais, 8.908 comerciais e 85.551 residenciais. Em relação à concentração dos consumidores de cada setor, as duas cidades compõem 51,4\% dos industriais, $44,6 \%$ dos comerciais e $41,6 \%$ das residências da RAA toda. Ainda assim, a oferta de gás não é capaz de suprir a demanda industrial que essas cidades gerariam. Considerando os 4 milhões de $\mathrm{m}^{3}$ por dia, disponíveis em Bilac, é possível fornecer gás apenas para 59,3\% das indústrias das duas cidades ou para todos os consumidores comerciais e residenciais, mais $54,3 \%$ dos consumidores industriais. 
A concessionária GBD apresenta em seu plano de negócio uma previsão de atendimento para usuários residenciais, comerciais e industriais para 2014, com parcial para o ano 2009. Rodrigues e colaboradores (2007), em seu trabalho sobre o mercado de gás natural no noroeste paulista, fazem a seguinte análise: adotando como base os dados disponíveis de quantidade real consumida de gás natural na região noroeste de São Paulo, no período de 2003 a 2006, e acrescentando a projeção de consumo fornecida pela empresa Gás Brasiliano para os anos de 2009 a 2014, traçou-se uma progressão linear que, neste artigo, ditaria o crescimento do insumo na região.

Tabela 7

Projeção da demanda de gás natural na RAA

\begin{tabular}{|c|c|c|c|c|c|}
\hline Ano & 2010 & 2015 & 2020 & 2025 & 2030 \\
\hline População urbana & 678.777 & 713.401 & 749.792 & 788.039 & 828.237 \\
\hline Atendimento (\%) & 10 & 46 & 66 & 85 & 100 \\
\hline Domicílios & 22.626 & 109.388 & 164.954 & 223.278 & 276.079 \\
\hline Consumo (m³/mês) & 19,0 & 19,0 & 19,0 & 19,0 & 19,0 \\
\hline Total urbano $\left(10^{6} \mathrm{~m}^{3} / \mathrm{mês}\right)$ & 0,43 & 2,08 & 3,13 & 4,24 & 5,25 \\
\hline Consum. comerciais & 19.990 & 19.990 & 19.990 & 19.990 & 19.990 \\
\hline Atendimento (\%) & 30 & 54 & 70 & 85 & 100 \\
\hline Consumo (103 m³/mês) & 0,9 & 0,9 & 0,9 & 0,9 & 0,9 \\
\hline Total comercial ( $\left.10^{6} \mathrm{~m}^{3} / \mathrm{mês}\right)$ & 5,40 & 9,72 & 12,59 & 15,29 & 17,99 \\
\hline Consumidores industriais & 3.840 & 4.451 & 5.160 & 5.982 & 6.935 \\
\hline Atendimento (\%) & 0 & 15 & 40 & 65 & 100 \\
\hline Consumo (103 m³/dia) & 300,0 & 300,0 & 300,0 & 300,0 & 300,0 \\
\hline Total industrial $\left(10^{6} \mathrm{~m}^{3} / \mathrm{mês}\right)$ & 5,18 & 200,30 & 619,21 & $1.166,48$ & $2.080,41$ \\
\hline Total geral ( $\left.10^{6} \mathrm{~m}^{3} / \mathrm{mês}\right)$ & 11,01 & 212,09 & 634,94 & $1.186,01$ & $2.103,65$ \\
\hline
\end{tabular}

De acordo com essa projeção, a GBD estaria distribuindo, em 2030, para toda a região de sua concessão apenas $30 \%$ do que a cidade de Araçatuba tem de potencial para consumir. Assim, o potencial reprimido hoje nunca seria plenamente satisfeito, o que significa que a RAA nunca apresentaria o mesmo padrão de consumo que a média de consumo de GN no estado paulista hoje.

O estudo sobre expansão da oferta de GN no Brasil (EPE, 2007a) aponta uma oferta de 110,785 milhões de $\mathrm{m}^{3}$ por dia nas regiões S/SE/CO até 2016. Se a oferta se mantiver até 2030, não é razoável esperar que as cidades de Araçatuba e Birigui sejam plenamente satisfeitas em relação ao potencial de 
consumo que elas apresentam hoje. Mesmo tais cidades sendo os polos mais atrativos da RAA, uma vez que parte da infraestrutura necessária (city-gate de Bilac) já existe para atender a essas cidades, o crescimento do mercado deve ser muito maior que o previsto no plano de negócio da GBD. Porém, o estudo da engenheira Rodrigues (2007) considera a projeção superestimada devido à relação que haveria entre o consumo da RAA e a oferta esperada pela EPE, e por estar muito além do potencial esperado pelo estudo do professor dr. Udaeta (Grimoni et al., 1999).

\section{Combustíveis carburantes}

A relação de habitantes por veículo da RAA é superior à da média do estado de São Paulo, fato que pode ser visto como um mercado reprimido de veículos. A demanda reprimida de combustível carburante será o combustível necessário para suprir essa potencial frota adicional. Assim, tomando como meta a RAA atingir a mesma relação habitantes/veículo do estado, a demanda reprimida de combustível será estimada multiplicando-se a frota reprimida de veículos pelo consumo médio dos mesmos.

O Detran fornece o total da frota de veículos no Brasil, porém o número total de veículos não corresponde à frota circulante, pois muitos veículos saem de circulação sem que a baixa seja dada no sistema. Portanto, para estimativa do consumo médio por veículos a álcool e a gasolina foram utilizados dados da Sindipeças (2008), como o tamanho da frota e a distribuição do tipo de combustível utilizado para os veículos classe automóveis, comerciais leves e motos.

O consumo nacional de álcool e gasolina considerado foi o do total das vendas das distribuidoras cadastradas pela ANP, assumindo-se a hipótese de que todo combustível é consumido por automóveis comerciais, leves e motos.

Para a estimativa da frota da RAA e do estado de São Paulo, foi utilizada a proporção de veículos cadastrados no Detran referente aos municípios da RAA e do estado de São Paulo multiplicado pelo total da frota circulante.

Para a estimativa do consumo médio de combustível por veículo foi incluído o número de motos presente na frota porque a demanda reprimida foi calculada em relação à proporção habitante por veículo. Porém, algumas ressalvas devem ser feitas. Em primeiro lugar em relação ao consumo, mais de $60 \%$ das motos possuem até $125 \mathrm{cc}$, ou seja, veículos que consomem até $35 \mathrm{~km} / \mathrm{l}$, cerca de quatro a seis vezes menos que um carro. A relação entre o total de motos no Brasil e no estado de São Paulo ou na RAA varia pouco no tempo e não apresenta uma tendência de crescimento ou queda, mas a proporção do total de 
motos pelo total de carros no Brasil é diferente da proporção para o estado de São Paulo e para a RAA. Além de apresentar um crescimento de 1,5 a 2 pontos percentuais em favor da frota de motos, o que pode até levar à redução de consumo por veículo no tempo.

Esta análise assegura que o consumo por veículo na RAA deve ser um pouco menor que a média nacional por conta da elevada proporção de motos na região. Para estimativa do consumo médio por veículo foi considerado o consumo médio dos anos 2005 a 2007, assumindo-se a hipótese que carros flex consomem apenas álcool e motos consomem apenas gasolina.

Como a taxa de crescimento das motos é muito maior que a taxa de crescimento dos carros, é trivial que o consumo de combustível por veículo a gasolina deve cair ao longo do tempo. Será aceita a hipótese de que o consumo dos carros a gasolina é quatro vezes maior que o das motos. Logo, é calculado o consumo unitário anual de motos e projetado o consumo de gasolina como a soma do consumo das motos e dos carros. O resultado da estimativa é apresentado na tabela 8 .

Tabela 8

Consumo médio de combustível por veículo na frota brasileira em litros por ano

\begin{tabular}{|lrrrr|}
\hline Tipo de veículo & 2005 & 2006 & 2007 & Média \\
\hline Álcool e gasolina & 1.030 & 1.038 & 1.066 & 1.045 \\
Álcool & 1.055 & 1.496 & 1.344 & 1.298 \\
Gasolina & 1.069 & 999 & 1.031 & 1.033 \\
Carros & 1.315 & 1.242 & 1.345 & 1.347 \\
Motos & 329 & 311 & 336 & 337 \\
\hline
\end{tabular}

Fonte: Sindipeças e ANP.

Com esses dados estima-se um consumo anual de combustível na RAA de 43,90 milhões de litros de álcool e 126,35 milhões de litros de gasolina em 2007.

Para estimativa do tamanho da frota reprimida na RAA foi tomada como base a taxa de habitantes por veículo em 2007 para a RAA e para o estado de São Paulo. A quantidade de veículos faltantes na frota da RAA para igualar as taxas seria uma medida considerada frota reprimida. Foi pesquisada a relação habitantes por veículos na Austrália (AAA, 2008) e EUA (FHWA, 2006; USCB, 2008) para o estudo de projeção da frota. Os dados da análise podem ser verificados na tabela 9. 
Tabela 9

Relação do número de habitantes pela quantidade de veículos

\begin{tabular}{|lccc|}
\hline Local & $\mathbf{2 0 0 5}$ & $\mathbf{2 0 0 6}$ & $\mathbf{2 0 0 7}$ \\
\hline Brasil & 8,4 & 8,2 & 7,8 \\
Estado de São Paulo & 4,2 & 4,1 & 3,8 \\
Região Administrativa de Araçatuba & 4,5 & 4,3 & 4,0 \\
Austrália & & 1,5 & \\
EUA & & 2,1 & \\
\hline
\end{tabular}

Fonte: Sindipeças; IBGE; Australian Automobile Association; FHWA.

Para os dados encontrados, a demanda reprimida de veículos na RAA foi estimada em 9.940 em relação à média do estado de São Paulo e em 185.447 em relação aos EUA. Considerando as distribuições de veículos a gasolina, a álcool e a diesel já discutido anteriormente, teria-se uma demanda reprimida de combustível (álcool e gasolina), conforme a tabela 10 .

Para a projeção do consumo de combustível carburante na RAA foi estimada a penetração de carros flex na frota brasileira e admitiu-se que na RAA a penetração ocorre da mesma forma. Ainda utilizando a hipótese de que todos os carros flex consomem apenas álcool e as motos devem consumir apenas gasolina, foi projetado o consumo de álcool e gasolina para o crescimento médio da frota nacional verificado nos últimos anos.

Tabela 10

Demanda reprimida de veículos e combustível na RAA

\begin{tabular}{|c|c|c|c|c|c|c|}
\hline \multirow[b]{2}{*}{ Tipo } & \multicolumn{2}{|c|}{$\begin{array}{c}\text { Relação ao estado } \\
\text { de SP }\end{array}$} & \multicolumn{4}{|c|}{ Relação aos EUA } \\
\hline & Veículos & $\begin{array}{l}\text { Combustível } \\
\text { (litros) }\end{array}$ & Veículos* & $\begin{array}{l}\text { Combustível } \\
\text { (litros)* }^{*}\end{array}$ & Veículos** & $\begin{array}{l}\text { Combustível } \\
\text { (litros) }^{* *}\end{array}$ \\
\hline Flex (álcool) & 1.904 & 2.472 .248 & 35.523 & 46.125 .419 & 108.554 & 140.953 .017 \\
\hline Gasolina & 4.443 & 5.982 .631 & 82.888 & 111.619 .632 & 9.902 & 13.334 .854 \\
\hline $\begin{array}{l}\text { Motos } \\
\text { (gasolina) }\end{array}$ & 3.305 & 1.112 .764 & 61.668 & 20.761 .145 & 61.668 & 20.761 .145 \\
\hline Diesel & 288 & - & 5.368 & - & 5.323 & - \\
\hline Total & 9.940 & $9.567 .642,2$ & 185.447 & $178.506 .196,4$ & 185.447 & $175.049 .016,3$ \\
\hline
\end{tabular}

* A demanda reprimida satisfeita segundo a proporção de carros em circulação por tipo de combustível.

** A demanda reprimida satisfeita segundo a proporção de vendas atual de carros por tipo de combustível. 
Segundo dados da Anfavea (MDIC, 2008) a venda de carros a gasolina está em torno de $8 \%$ no ano (jan. a mar. 2008) e os carros importados compreendem cerca de $10 \%$ do mercado nacional, assume-se que $8 \%$ deve ser o número mínimo da participação nas vendas dos carros a gasolina no mercado nacional de carros novos. A fatia dos carros a diesel será assumida 4,3\% e flex $87,7 \%$. De 2003 a 2007, as vendas de automóveis e veículos leves cresceram a uma taxa média de $16 \%$ ao ano.

Como conceito de sucateamento de carros, ou sobrevivência dos veículos, a Sindipeças utiliza um total de perdas de $1,5 \%$ ao ano ( $1 \%$ acidentes graves com perda total e $0,5 \%$ roubo sem recuperação), que também é utilizada aqui. O crescimento médio da frota de motos, para os últimos anos, é igual a $15,5 \%$ ao ano o que já inclui sucateamento.

Para a projeção da frota nacional, é usada a taxa de crescimento de motos e carros observada para os últimos anos, até 2012. A partir desse ano adota-se uma função exponencial para o crescimento da frota, com base na evolução da relação habitante por veículo da Austrália (AAA, 2008). Como o número de motos em relação ao total de veículos está aumentando nos últimos anos, quando adotada a função exponencial, dos veículos incorporados no mercado, $60 \%$ devem ser automóveis e $40 \%$ motocicletas.

Acredita-se que o acentuado volume de vendas observado nos últimos anos é devido à absorção dos veículos flex pelo mercado. Em 2012, mantendo esse ritmo de crescimento, $50 \%$ da frota nacional deve ser bicombustível. A partir desse ano a busca por carros flex deve diminuir e as vendas devem cair.

Tabela 11

Projeção da frota nacional de veículos e consumo de combustível carburante

\begin{tabular}{|lcrrrrr|}
\hline Discriminação & 2010 & \multicolumn{1}{c}{2012} & 2015 & 2020 & \multicolumn{1}{c}{2025} & \multicolumn{1}{c}{2030} \\
\hline Álcool & 2.466 .284 & 2.392 .850 & 2.286 .779 & 2.120 .339 & 1.966 .014 & 1.822 .920 \\
Flex & 12.429 .194 & 20.032 .930 & 22.921 .147 & 28.056 .974 & 32.696 .427 & 37.648 .052 \\
Gasolina & 16.288 .924 & 16.531 .293 & 16.142 .957 & 15.588 .687 & 15.063 .578 & 14.635 .968 \\
Diesel & 1.410 .136 & 1.759 .111 & 1.866 .285 & 2.064 .061 & 2.241 .432 & 2.437 .757 \\
Vendas de carros & 3.654 .107 & 4.916 .967 & 1.490 .210 & 1.672 .620 & 1.627 .845 & 1.786 .692 \\
Motos & 11.146 .884 & 12.289 .439 & 13.956 .762 & 17.032 .024 & 19.790 .283 & 22.841 .781 \\
Veículos total & 43.741 .421 & 53.005 .624 & 57.173 .930 & 64.862 .085 & 71.757 .735 & 79.386 .478 \\
\hline
\end{tabular}




\begin{tabular}{|c|c|c|c|c|c|c|c|}
\hline \multicolumn{2}{|c|}{ Discriminação } & 2010 & 2012 & 2015 & 2020 & 2025 & 2030 \\
\hline \multirow{2}{*}{ Brasil* } & Álcool & $19.341,1$ & $29.118,9$ & $32.731,4$ & $39.183,9$ & $45.007,7$ & $51.251,4$ \\
\hline & Gasolina & $25.688,0$ & $26.399,0$ & $26.437,4$ & $26.726,3$ & $26.947,8$ & $27.399,3$ \\
\hline \multirow{2}{*}{ RAA* } & Álcool & 100,6 & 151,4 & 170,2 & 203,8 & 234,0 & 266,5 \\
\hline & Gasolina & 133,6 & 137,3 & 137,5 & 139,0 & 140,1 & 142,5 \\
\hline \multicolumn{2}{|c|}{ Pop. BR ( $10^{3}$ hab.) } & $196.471,6$ & $200.420,7$ & $206.493,6$ & $217.026,9$ & $225.847,9$ & $235.027,6$ \\
\hline \multicolumn{2}{|c|}{$\begin{array}{l}\text { Pop. RAA }\left(10^{3}\right. \\
\text { hab.) }\end{array}$} & 771,4 & 786,9 & 810,8 & 852,1 & 895,6 & 941,3 \\
\hline \multicolumn{2}{|c|}{ Hab./Veíc. BR } & 4,5 & 3,8 & 3,6 & 3,3 & 3,1 & 3,0 \\
\hline \multicolumn{2}{|c|}{ Hab./Veíc. RAA } & 3,0 & 2,5 & 2,4 & 2,2 & 2,1 & 2,0 \\
\hline
\end{tabular}

* Consumo de combustível em milhões de litros.

Segundo essa projeção, o consumo nacional de gasolina, que em 2007 foi de 24.325,4 milhões de litros, deve alcançar apenas 27.399,3 milhões de litros em 2030, aumentando fortemente o consumo de etanol. Em 2007, o consumo de álcool foi de 9.366,8 milhões de litros, e segundo a projeção o consumo em 2030 deve ser de cerca de 51.251,4 milhões de litros. É importante confrontar tais dados com o Plano Nacional de Energia 2030 (PNE 2030), que projeta o consumo de gasolina e álcool conforme é apresentado na tabela 12 .

Tabela 12

Consumo de combustível carburante projetado no PNE 2030

\begin{tabular}{|lccc|}
\hline PNE 2030 & 2010 & 2020 & 2030 \\
\hline Álcool & 20.000 & 32.500 & 54.000 \\
Gasolina & 19.580 & 26.229 & 42.190 \\
\hline
\end{tabular}

Fonte: EPE.

* Consumo de combustível em milhões de litros.

O consumo de álcool estimado nessa projeção está aderente com a projeção feita pela EPE. Porém, o consumo de gasolina feito pela EPE parece não estar de acordo com a realidade, dado que o consumo atual é superior ao projetado para 2010.

O consumo de álcool estimado nessa projeção para a RAA em 2030 foi de 266,5 milhões de litros e 142,5 milhões de litros de gasolina. Nesse ano, a relação habitante por veículo seria de 2,0. 


\section{Conclusões}

O consumo mensal médio residencial foi de 191,5 kWh por domicílio em 2007 (Sabesp, 2008). Considerando o modelo da tabela 3, em uma residência simples com itens elétricos para prover conforto a três pessoas, o consumo estimado é de $207 \mathrm{kWh}$ mensal por domicílio. A demanda reprimida no Brasil referese não apenas a domicílios sem acesso à energia mas, principalmente, ao não acesso de pessoas a itens básicos para o conforto como geladeira, chuveiro e aparelhos para controle do clima, mesmo um simples ventilador.

A demanda elétrica total reprimida na RAA foi estimada em 22.467 MWh mensais em relação ao estado, o que representa uma potência instalada de $52 \mathrm{MW}$, uma termelétrica média. Em relação ao consumo da Flórida a demanda reprimida total foi estimada em 477.052 MWh mensais, o que equivale a uma capacidade instalada de $1.100 \mathrm{MW}$.

Para o gás distribuído pela GBD a demanda reprimida em relação à média de consumo do estado é de 926,28 milhões de $\mathrm{m}^{3}, 26$ milhões de $\mathrm{m}^{3}$ a mais do que os 900 milhões de $\mathrm{m}^{3}$ que o Gasbol pode transportar por mês. $\mathrm{O}$ que mostra que a região é carente desse serviço não só porque não possui infraestrutura para distribuição, mas porque não há oferta suficiente para suprir a demanda que uma infraestrutura adequada poderia gerar. Por outro lado, em um estudo mais aprofundado, segundo Udaeta (Grimoni e colaboradores, 1999), o potencial da região seria de apenas 3,80 milhões de $\mathrm{m}^{3} /$ mês, pouco mais que o dobro que é distribuído hoje pelo city-gate de Bilac.

A demanda reprimida de veículo em relação à média do estado de São Paulo foi baixa, cerca de 5\%, resultando em uma demanda reprimida de menos de 10 milhões de litros anuais (álcool e gasolina). Em relação aos EUA, o consumo de álcool estimado para a RAA, caso a demanda reprimida fosse satisfeita segundo a distribuição atual de vendas de carros, seria de 185 milhões de litros e de gasolina cerca de 160 milhões de litros. Com uma produção atual de cerca de 2 bilhões de litros de álcool, a RAA tem potencial para suprir sua necessidade e exportar muito álcool, utilizando 9,5\% do seu território em área plantada de cana.

A biomassa de cana, sem dúvida, apresenta um enorme potencial energético para a região. $O$ produtor de cana que já otimiza sua produção para decidir quanto produzirá de álcool e açúcar, em breve, com o emprego da hidrólise, terá um outro fator de decisão igualmente rentável: quanto de bagaço será destinado para a produção de energia ou para álcool. Hoje, alguns usineiros produzem bagaço como matéria-prima primária, tendo mais de $25 \%$ da sua receita oriunda da geração de eletricidade. 
Apenas como demonstração, empregando a tecnologia de ciclo a vapor com turbinas de condensação e extração, já bastante usada nas novas usinas, somente na RAA o potencial teórico de geração de energia elétrica com a palha da cana-de-açúcar seria de $5.283 \mathrm{GWh}$ por ano, cerca de cinco vezes o consumo atual total da RAA.

Observa-se que até hoje o Brasil sofre uma espécie de racionamento por meio do preço dos energéticos. $\mathrm{O}$ alto custo da energia em determinadas regiões impede que ela seja ofertada a um valor acessível em outras regiões que possuem potencial para gerar mais energia do que geram. E, principalmente, a falta de acesso a equipamentos domésticos e industriais por grande parte da população faz com que o consumo de energia seja baixo onde a energia é ofertada. A RAA, pela má distribuição da renda e pouco poder aquisitivo da população sofre o efeito desse tipo de racionamento, impedindo que a demanda reprimida da região seja atrativa a investimentos para gerar oferta.

Contudo, embora a região apresente um bom IDH e grande potencial de crescimento econômico, com a economia razoavelmente bem-sucedida, a infraestrutura do setor energético da região é carente. Isso, sem dúvida, é um entrave para o crescimento da região.

\section{Referências}

AUSTRALIAN AUTOMOBILE ASSOCIATION. Total number of registered vehicles. Disponível em: <www.aaa.asn.au/documents/stats/30.xls>. Acesso em: 16 jun. 2008.

. Population, Australian states and territories. Disponível em: <www.aaa. asn.au/documents/stats/22.xls> . Acesso em: 16 jun. 2008.

BBC Brasil. Discussão sobre álcool expôs más condições em canaviais, diz "Guardian". Folha Online, São Paulo, 2008. Disponível em: <www1.folha.uol.com. br/folha/bbc/ult272u409009.shtml>. Acesso em: 6 jun. 2008.

BURNQUIST, H. L. et al. Análise conjuntural - análise sobre o setor sucroalcooleiro elaborada pelo Cepea. 2008. Disponível em: <www.cepea.esalq.usp.br/agromensal /2008/04_abril/AcucarAlcool.htm\#_II_-_S\%E9ries_1 >. Acesso em: 5 jun. 2008.

CONAB (Companhia Nacional de Abastecimento). Acompanhamento da safra brasileira cana-de-açúcar 2008/09 - primeiro levantamento, abril/2008. Brasília, 2008. Disponível em: <www.conab.gov.br/conabweb/download/safra/cana.pdf> . Acesso em: 5 jun. 2008. 
DSR (Divisão de Sensoriamento Remoto do Inpe). Canasat. Disponível em: <www. dsr.inpe.br/mapdsr/frame.jsp > . Acesso em: 7 jul. 2008.

EPE (Empresa de Pesquisa Energética). Planejamento decenal de expansão da energia elétrica 2007-2016. Rio de Janeiro, 2007a. Disponível em: <www.epe.gov.br>. Acesso em: 10 nov. 2007.

. Plano nacional de energia 2030. Rio de Janeiro, 2007b. Disponível em: <www.epe.gov.br>. Acesso em: 10 nov. 2007.

FHWA (Federal Highway Administration). State Motor Registrations - 2006. Disponível em: <www.fhwa.dot.gov/policy/ohim/hs06/htm/mv1.htm>. Acesso em: 16 jun. 2008.

FLORIDA PUBLIC SERVICE COMMISSION. Ten year power plant site plan 20072016. Florida Power \& Light Company, p. 33-34, Miami, Florida, 2007. Disponível em: <www.fpl.com/a bout/ten_year/pdf/plan.pdf>. Acesso em: 6 nov. 2007.

GRIMONI, J. A. B. et al. Estimativa dos recursos energéticos da região de Araçatuba. São Paulo, 1999.

IBGE (Instituto Brasileiro de Geografia e Estatística). Planilha eletrônica com os dados do PIB por municípios até 2005. Disponível em: <www.ibge.com.br/home/>. Acesso em: 16 jun. 2008.

LEITE, R. C. C. Biomassa, a esperança verde para poucos. Folha de S.Paulo, São Paulo, 2005. Disponível em: <www1.folha.uol.com.br/fsp/opiniao/fz2502200509. htm>. Acesso em: 16 jun. 2008.

MDIC (Ministério do Desenvolvimento, Indústria e Comércio Exterior). Álcool combustível. Disponível em: <www.mdic.gov.br/sitio/interna/interna.php?area $=2 \&$ menu=999>. Acesso em: 5 jun. 2008.

OMETTO, D. DHR (Dedini Hidrólise Rápida). Inova Unicamp, 2003. Disponível em: <www.inova.unicamp.br/inventabrasil/dedini.htm>. Acesso em: 5 jun. 2008.

RODRIGUES, R. G. B. Análise do cenário atual e aspectos de demanda do gás natural - Carteira de recursos energéticos visando o gás natural dentro do PIR para Região Administrativa de Araçatuba. 2007. Monografia (Graduação em Engenharia Elétrica) — Escola Politécnica da Universidade de São Paulo, São Paulo.

SABESP (Secretaria de Saneamento e Energia do Estado de São Paulo). Balanço energético estadual de São Paulo - 2008: ano-base 2007. Disponível em: <www. saneamento.sp.gov.br>. Acesso em: 10 jun. 2008.

SINDIPEÇAS (Sindicato Nacional da Indústria de Componentes para Veículos Automotores). Estudo da frota circulante brasileira. São Paulo, 2008. Disponível 
em: <www.sindipecas.org.br/paginas_NETCDM/modelo_pagina_generico.asp?ID_ CANAL $=103>$. Acesso em: 16 jun. 2008.

UDOP (União dos Produtores de Bioenergia). Dados de produção de cana-de-açúcar — safra 94/95 a 06/07. Disponível em: <www.udop.com.br/>. Acesso em: 5 jun. 2008.

U. S. CENSUS BUREAU. State \& county quickfacts. Disponível em: < http://quickfacts.census.gov/qfd/states/00000.html>. Acesso em: 16 jun. 2008. 